\title{
Influence of optimizing prosumers on rural distribution networks
}

\author{
M. A. Lagler®i, R. Schürhuber
}

A plethora of factors is currently leading to significant changes in both the planning and operation of distribution networks and systems, such as single-family houses and commercial and industrial buildings. These factors include the increasing share of decentralized energy generation and storage systems in distribution networks, the integration of electric vehicles, the coupling of electrical and thermal systems, as well as the increasing and easy use of Information and Communication Technologies (ICT). The primary actors in this situation, formerly known as consumers of energy and power, have now become prosumers (producers and consumers), who feed energy back into the network at specific times.

Hybrid energy systems combine cross-sectoral energy sources and supply systems as well as energy distribution and storage to form one compact system. The aim is to substitute fossil energy sources with primarily renewably generated electricity, other renewable energy sources, and sustainable ways of energy usage. Moreover, the use of new meter functions and services enables marketdependent dynamic or special consumer- and prosumer-oriented tariffs.

A simulation model has been developed to model, simulate, and analyze the behavior and steady-state energy flows of such hybrid energy systems. By using linear optimization algorithms, the optimal use of decentralized energy generation and storage systems is determined in the example of a single-family house. The simulation model considers different optimization objectives, desired energy services, external boundary conditions, individual technical components, as well as selected energy tariffs. Furthermore, the simulation model is used to analyze how the high penetration of optimizing prosumers influences rural distribution networks.

Keywords: hybrid energy system; photovoltaic; storage; optimizing prosumers; single-family house; MILP; load-flow calculations; energy tariffs

\section{Einfluss optimierender Prosumer auf rurale Verteilnetze.}

Der steigende Anteil dezentraler Energieerzeugungs- sowie Speicheranlagen in den Verteilnetzen, die Integration von Elektrofahrzeugen, die Kopplung von elektrischen und thermischen Systemen sowie die steigende und einfache Nutzung von Informations- und Kommunikationstechnologien (IKT) führen zu starken Veränderungen hinsichtlich der Planung und des Betriebs von Verteilnetzen und Anlagen wie Einfamilienhäusern sowie Gewerbe- und Industriegebäuden. Die Hauptakteurlinnen in dieser Situation, vormals reine Energie- und Leistungskonsument/innen, werden nun zu sogenannten Prosumern (Producer und Consumer), welche zu bestimmten Zeiten z. B. elektrische Energie in das Netz rückspeisen.

Ein hybrides Energiesystem weist eine intelligente Kopplung der Energieerzeugungs- und Speicheranlagen des Strom-, Wärmeund Kältesektors auf. Durch diese sektorenübergreifende Kopplung kann der elektrische sowie thermische Energiebedarf ökonomisch und/oder ökologisch effizient gedeckt werden. Hybride Energiesysteme haben zum Ziel, fossile Energieträger durch überwiegend regenerativ erzeugten Strom, andere erneuerbare Energiequellen sowie durch nachhaltige Formen der Energienutzung zu substituieren. Weiters ermöglicht die Verwendung neuer Zählerfunktionen und -dienste marktabhängige dynamische oder spezielle verbraucherund prosumerorientierte Tarife.

Es wurde ein Simulationsprogramm entwickelt, mit welchem das Verhalten sowie die stationären Energieflüsse solcher hybrider Energiesysteme modelliert, simuliert und analysiert werden können. Mit linearen Optimierungsalgorithmen wird der optimale Einsatz von dezentralen Energieerzeugungs- und Speichersystemen am Beispiel eines Einfamilienhauses ermittelt. Das Simulationsprogramm berücksichtigt unterschiedliche Optimierungsziele, gewünschte Energiedienstleistungen, äußere Randbedingungen, die eingesetzten technischen Anlagen sowie ausgewählte Energietarife. Darüber hinaus wird mithilfe des Simulationsprogramms der Einfluss von optimierenden Prosumern auf ländliche Verteilnetze untersucht.

Schlüsselwörter: hybride Energiesysteme; Photovoltaik; Speicher; optimierende Prosumer; Einfamilienhaus; MILP; Lastflussrechnungen; Energietarife

Received July 12, 2021, accepted October 11, 2021, published online October 25, 2021

(c) The Author(s) 2021

\section{Introduction}

Traditionally, a certain sum of single-family houses were consumers with a predictable load profile, periodically repeated over days and weeks. These loads' behaviour has been changing in recent years due to the fall in price and development of renewable generation and storage systems, the more accessible use of Information and Communication Technologies (ICT), the changing environ- mental awareness of people, and the push for more autonomy. The increasing share of decentralised energy generation and storage systems, the integration of electric vehicles, and the coupling

Lagler, Mike Alexander, Institute of Electrical Power Systems, Graz University of Technology, Inffeldgasse 18/I, 8010 Graz, Austria (E-mail: lagler@tugraz.at); Schürhuber, Robert, Institute of Electrical Power Systems, Graz University of Technology, Graz, Austria 


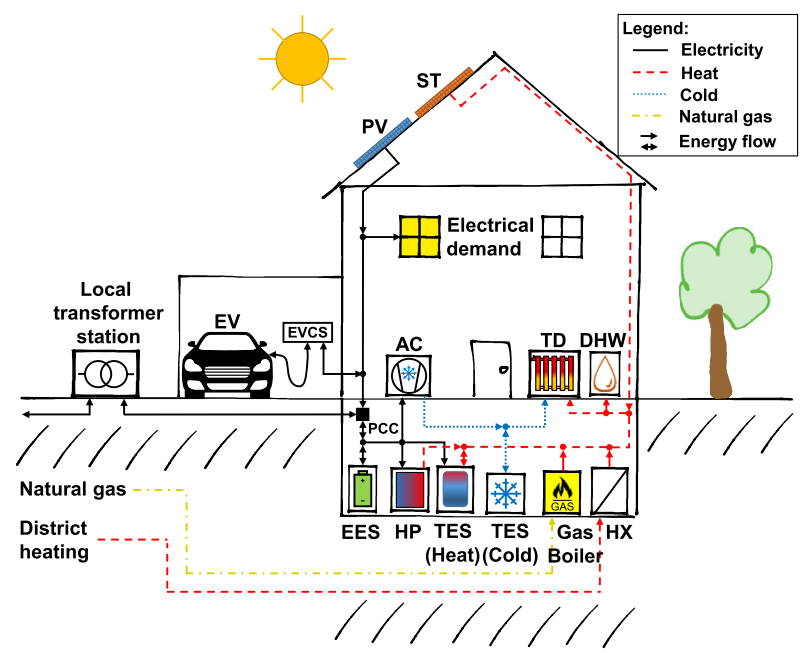

Fig. 1. Schematic illustration of a prosumer.

AC ... Air conditioner; PCC ... Point of common coupling;

DHW ... Domestic hot water; PV ... Photovoltaic system;

EES ... Electrical energy storage; ST ... Solar thermal storage;

EV ... Electric vehicle; TES ... Thermal energy storage;

EVCS ... EV charging station; TD ... Thermal demand;

$\mathrm{HX}$... Heat Exchanger

of electrical and thermal systems leads to significant changes in both the planning and operation of distribution networks and systems such as single-family houses, commercial and industrial buildings.

The primary actors in this situation, formerly known as consumers of energy and power, have now become so-called prosumers (producers and consumers) who feed energy back into the network at specific times. With the help of ICT methods and optimisation algorithms, prosumers can react to market-dependent dynamic or consumer and prosumer-oriented tariffs in order to achieve a specific individual, e.g., economic or ecological, optimum.

The following Fig. 1 gives an overview of a prosumer by the example of a single-family house and shows commonly used technologies for energy supply and storage. Figure 1 do not represent a recommendation for simultaneous implementation of all these technologies in a single-family house.

The key components for coupling the thermal and electrical energy systems to a hybrid energy system are the heat pump (HP), the air conditioning system $(A C)$ and the heating cartridges of the thermal energy storage.

In this contribution, a simulation model, developed at the Institute of Electrical Power System of TU Graz, is used to model, simulate and analyse the behaviour and steady-state energy flows of hybrid energy systems such as single-family houses shown in Fig. 1. Using linear optimisation algorithms, the simulation model determines in a forecast-based manner the optimal use of decentralised energy generation and storage systems. It does so by considering different optimisation objectives, desired energy services (heating, cooling, electrical energy services), external boundary conditions (e.g., building structure, weather), individual technical components, as well as selected energy tariffs

Furthermore, the simulation model is used to analyse how a high penetration of optimising prosumers influences rural distribution networks.

\section{Simulation model}

The simulation model, developed with the software MATLAB, is used to analyse the behaviour of optimising prosumers. Therefore, the simulation model performs steady-state energy flow calculations for the hybrid energy system of a prosumer.

With the simulation model, the optimal use of the decentralised energy generation and storage systems can be determined based on scenarios using mixed-integer linear programming (MILP), depending on various objective functions such as

- the reduction of the annual energy costs,

- to minimisation of the $\mathrm{CO}_{2}$-emissions, or

- the increase of the usage of the generated energy of the decentralised generation systems.

By optimising the use of distributed generation systems (e.g., photovoltaics, solar thermal) and energy storages the prosumer can respond to dynamic tariffs and obtain, e.g., an economically optimal advantage.

The simulation model is structured into four interdependent main parts - Inputs, Settings, Calculations and Optimisation -, which get executed in this order.

The optimisation is performed in a temporal time resolution of 15 minutes over the time span of one year. Since long-term forecasts of weather and demand have a high degree of uncertainty, the optimisation algorithm take a short forecast time of, e.g. the upcoming three days (72 hours) into account.

The following list outlines possible applications for the simulation model according to the energy-based analysis of prosumers.

- Optimisation of the prosumers operation considering various objectives, such as increasing the degree of self-consumption or achieving an economically or ecologically optimal advantage.

- Dimensioning and optimal operation of generation and storage systems.

- Coupling a prosumer's thermal and electrical energy system.

- Analysis of various energy tariffs' influence on the operation of prosumers.

- Integration of electric vehicles including Vehicle2Grid/Grid2Vehicle.

- Determination of the behaviour of optimising prosumers in lowvoltage distribution networks taking into account voltage and reactive power control.

\subsection{Optimisation of hybrid energy systems}

The method of linear programming represents procedures for the mathematical solution of a specific class of linear extreme value problems with constraints. In the mathematical context, an optimisation determines the maximum or the minimum of a function $F(\mathbf{x})$. This function $F(\mathbf{x})$ is defined here on a (restricted) state space. The decisions to be made by the optimisation algorithm, e.g., choosing the shortest possible way, are represented by variables $\mathbf{x}$ (degrees of freedom). To determine an optimal solution of the optimisation problem, exact methods such as decision tree (Branch\&Bound and Branch\&(ut algorithms) and cutting plane methods can be applied [1]. Mixed-integer problems can be described in the form ${ }^{1}$

$$
\min _{\mathbf{x}} \mathbf{c}^{\top} \cdot \mathbf{x} \text { subject to }\left\{\begin{array}{c}
\mathbf{x}(\text { intcon }) \\
\mathbf{A}_{\text {neq }} \cdot \mathbf{x} \leq \mathbf{b}_{\text {neq }} \\
\mathbf{A}_{\text {eq }} \cdot \mathbf{x}=\mathbf{b}_{\text {eq }} \\
\mathbf{I}_{\mathrm{b}} \leq \mathbf{x} \leq \mathbf{u}_{\mathrm{b}}
\end{array}\right.
$$

${ }^{1}$ Definition: Bold lowercase letters correspond to a column vector; bold uppercase letters correspond to a matrix. 


$\begin{array}{ll}\mathbf{x} & \ldots \text { Variables (unknowns) } \\ \mathbf{A}_{\text {neq }}, \mathbf{A}_{\text {eq }} & \ldots \text { In- and equality system matrix } \\ \mathbf{b}_{\text {neq }}, \mathbf{b}_{\text {eq }} & \ldots \text { In- and equality constants (knowns) } \\ \mathbf{I}_{\mathrm{b}}, \mathbf{u}_{\mathrm{b}} & \ldots \text {. Lower and upper boundary of unknown variables } \\ \mathbf{c}^{\top} & \ldots \text { Objective function }\end{array}$

with the variables $\mathbf{x}=\left[\mathbf{x}_{r}, \mathbf{x}_{h}\right]^{\top} \in \mathbb{R}^{r+h}$ as integers $\mathbf{x}_{r}=$ $\left[x_{1}, x_{2}, \ldots, x_{r}\right]^{\top} \in \mathbb{Z}^{r}$ and as real numbers $\mathbf{x}_{h}=\left[x_{1}, x_{2}, \ldots, x_{h}\right]^{\top} \in$ $\mathbb{R}^{h}$. Binary variables are integers that can take only the values 0 and 1 . The system of linear equations consists of $m$ equations and $n=r+h$ unknowns, with which the equality system matrix $\mathbf{A}_{\mathrm{eq}}$ can be defined with $\mathbf{A}_{\text {eq }} \in \mathbb{R}^{m \times n}$. The same applies to the system of linear inequations. The linear system of inequations can be specified with $\mathbf{A}_{\text {neq }} \in \mathrm{R}^{m \times n}$ for $k$ inequalities and $n$ unknowns [2].

In the following, MILP is used to solve specific problems of hybrid energy systems, such as storage management or the most efficient use of the available technologies shown in Fig. 1. A advantage of MILP is that variables could also be integers or binary, e.g., on-off decisions of technologies. In MILP, mathematical modelling and profound knowledge of the entire system in order to properly set up the variables and the mathematical formulation of their relationships to each other is of crucial relevance [1].

The linear equality constraints $\left(\mathbf{A}_{\mathrm{eq}} \cdot \mathbf{x}=\mathbf{b}_{\mathrm{eq}}\right)$ form a system of linear equations described by the equality system matrix $\mathbf{A}_{\mathrm{eq}}$, several unknowns $\mathbf{x}$ (energy flow) and known coefficients $\mathbf{b}_{\text {eq }}$. The elements of the system matrix $\mathbf{A}_{\text {eq }}$ contain the efficiencies, conversion factors and losses for each technology and system component. The known variables $\mathbf{b}_{\text {eq }}$ consider the demand, as well as initially the state of charge of the storage systems. The variables $\mathbf{x}$ are limited by boundaries $\left(\mathbf{I}_{\mathrm{b}} \leq \mathbf{x} \leq \mathbf{u}_{\mathrm{b}}\right)$, resulting in the maximum transferred power or the maximum capacity of the respective storages. The system matrix $\mathbf{A}_{\mathrm{eq}}$, together with defined boundaries $\left(\mathbf{I}_{\mathrm{b}}, \mathbf{u}_{\mathrm{b}}\right)$, represents the physical connections of all technical systems as well as the possible directions of the energy flow.

In special cases, like the thermal energy storage shown in Fig. 1, modelled with two different temperature zones, linear inequality constraints $\left(\mathbf{A}_{\text {neq }} \cdot \mathbf{x}=\mathbf{b}_{\text {neq }}\right.$ ) must be used.

The optimisation algorithm, under the specification of an objective function $\mathbf{c}^{\top} \cdot \mathbf{x}$ (e.g., minimising cost or increase of degree of autonomy), solves the optimisation problem.

The simulation model simulates the energy flows - integral of power at a fixed time resolution - of the hybrid energy system of a prosumer instead of power flows, since the state of charge of the storages require the physical quantity "energy" and choosing a uniform quantity for all variables avoids possible mix-ups.

The system, shown in Fig. 1, can be described with $n=32$ variables, $m=13$ equations and $k=2$ inequalities. In order to achieve optimal storage management, it is essential to consider the next hours using a forecast of the demand, weather and energy tariffs. The size of the vectors and matrices of the constraints changes according to the considered next hours of the forecast with the total number of time steps $T$, e.g., a forecast of 72 hours with a temporal time resolution of 15 minutes corresponds to a total number of time steps $T=288$. Thus the constraints increase to $\mathbf{A}_{\mathrm{eq}}^{(m \times n) \cdot T} \cdot \mathbf{x}^{n \cdot T}=\mathbf{b}_{\mathrm{eq}}^{m \cdot T}$ and $\mathbf{A}_{\text {neq }}^{(k \times n) \cdot T} \cdot \mathbf{x}^{n \cdot T}=\mathbf{b}_{\text {neq }}^{k \cdot T}$

\section{Optimal operation of a prosumer}

The energy demand of a single-family house is based on the electrical demand - domestic appliances and lighting - and the thermal demand, such as heating, cooling and domestic water heating. Furthermore, the construction of the building strongly influences the heating and cooling behaviour. With a share of $85 \%$ of the total energy demand of households, space and domestic water heating
Table 1. Initial parameter settings - Prosumer

\begin{tabular}{|c|c|}
\hline Photovoltaic system: & $P=6,1 \mathrm{kWp}$ \\
\hline Electrical energy storage: & $W=7 \mathrm{kWh}$ \\
\hline Thermal energy storage: & $V=300$ litres \\
\hline Heating cartridge: & $P=2 \mathrm{~kW}$ \\
\hline Heat pump: & $P=7,63 \mathrm{~kW}_{\text {th }}(\mathrm{A} 2 \mathrm{~N}$ 35) \\
\hline Air conditioner: & $P=8,11 \mathrm{~kW}_{\text {th }}(\mathrm{A} 35 \mathrm{M} 18)$ \\
\hline Electrical demand: & $W=4700 \mathrm{kWh} / \mathrm{a}$ \\
\hline Electric vehicle: & $W=1000 \mathrm{kWh} / \mathrm{a}$ \\
\hline Heating demand: & $\begin{array}{l}W=75 \mathrm{kWh} / \mathrm{m}^{2} \mathrm{a} \\
\text { (min. indoor temp. } \vartheta=22^{\circ} \mathrm{C} \text { ) }\end{array}$ \\
\hline Cooling demand: & $\begin{array}{l}W=6 \mathrm{kWh} / \mathrm{m}^{2} \mathrm{a} \\
\text { (max. indoor temp. } \vartheta=26^{\circ} \mathrm{C} \text { ) }\end{array}$ \\
\hline Domestic hot water: & $\begin{array}{l}W=2063 \mathrm{kWh} / \mathrm{a} \\
\left(\max . \text { water temp. } \vartheta=60^{\circ} \mathrm{C}\right)\end{array}$ \\
\hline Building: & $A=72 \mathrm{~m}^{2}$ (conditioned floor area) \\
\hline
\end{tabular}

have a significant impact on hybrid energy systems. Additional, the charging of an electric vehicle is considered in the analyses.

Focus of the following analyses lies in the resulting electrical demand of prosumers, when the electrical and thermal systems are coupled together to a hybrid energy system. For this purpose, a heat pump is used to cover the heating demand and an air conditioning system to cover the cooling demand. In the following, a photovoltaic system in combination with electrical and thermal energy storages is used to cover a certain amount of the energy demand of the singlefamily house.

In general, the following analyses are carried out to investigate an optimising prosumer:

\section{Degree of autonomy and self-consumption of a prosumer}

The degree of autonomy as well as the degree of self-consumption are essential indicators to evaluate the efficient use of energy generated by renewable energy systems such as photovoltaic systems (PV). A detailed analysis of the degrees of autonomy and selfconsumption achievable by a prosumer, considering varying electrical generation and storage systems, is performed.

\section{Impact of energy tariffs on prosumer behaviour}

Since consumption and generation do not coincide in every time step, without the use of energy storages or demand-side management, it is possibly necessary to purchase or feed-in energy at suboptimal tariffs or to adapt the load profile (i.e. consumer behaviour) according to the tariff situation. The impact of tariff regimes commonly used in Austria, the static, high and low tariffs (HT/NT) and a newly offered dynamic tariff are investigated.

As the operation of the prosumer depends strongly on the demand and technology, the following initial parameter settings and loads are selected for simulations.

3.1 Degree of autonomy and self-consumption of a prosumer In a PV-Storage system, the generated electrical energy is consumed either instantaneously or at a later time using storage systems. The degree of autonomy DA and the degree of self-consumption DSC are essential indicators in evaluating the efficient use of the energy generated by renewable generation systems such as PV systems. Both indicators can be expressed as follows.

- The degree of autonomy DA indicates the share of demand covered by the PV combined with the electrical energy storage EES. The degree of autonomy thus indicates the independence from the power network $[3,4]$. 


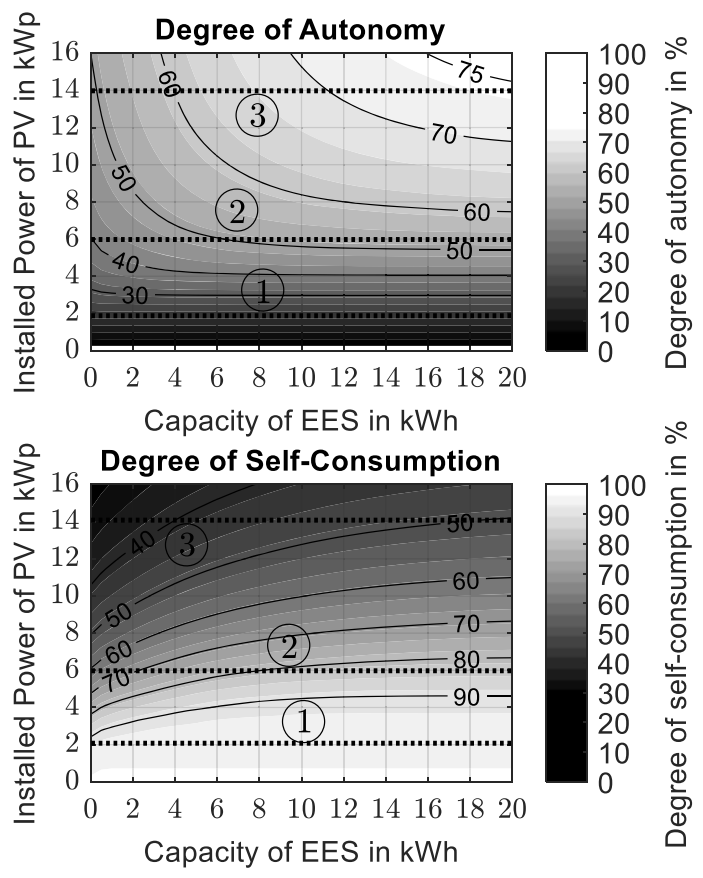

Fig. 2. Degree of autonomy and self-consumption of the investigated prosumers

- The degree of self-consumption DSC specifies how much of the PV's generated energy is consumed by the prosumer. The higher the degree of self-consumption, the less energy is fed into the power network by the PV system [3-5]

In the following and starting from the initial parameter settings stated in Table 1, the sensitivities of the DA and DSC according to varying PV and EES system sizes are evaluated.

Figure 2 graphically represents the calculated DA and DSC as contour-plots. In a contour plot, areas with the same colour and along the shown isolines correspond to the same degrees of autonomy DA and self-consumption DSC

Based on a given PV system, the DA and DSC improvements by using an EES system can be determined. In the following, the influence of different EES system capacities on the DA and DSC for three selected PV systems (1): $2 \mathrm{kWp}$, (2): $6 \mathrm{kWp}$, (3): $14 \mathrm{kWp}$ ) is examined in detail.

(1) The installation of a $2 \mathrm{kWp}$ PV system without using an EES leads to a DA of $18.1 \%$. Due to the high DSC of $94 \%$ achieved by the $\mathrm{PV}$ system alone, the EES usage results only in a marginal increase of the DA of $0.2 \%$ to $18.3 \%$. Nearly the entire PV generation is consumed instantaneously by the prosumer.

(2) The installation of a $6 \mathrm{kWp}$ PV system, commonly installed in Austrian household sector, leads to a degree of autonomy of $40 \%$. The DA can be increased by using an EES system. With an EES capacity of $20 \mathrm{kWh}$, the DA is increased to $53 \%$. However, there is no significant increase in the DA above a storage capacity of approximately $7 \mathrm{kWh}$. An increase of the EES capacity from 7 $\mathrm{kWh}$ to $20 \mathrm{kWh}$, thus a tripling of capacity, increases the DA just by $3 \%$ from $50 \%$ to $53 \%$.

This means that the EES with a storage capacity of $7 \mathrm{kWh}$ already uses most of the available surplus generation of the PV system. Larger EESs are not entirely utilised and increase the DA and DSC only in a few moments of the year where the $7 \mathrm{kWh}$ EES would be already fully charged.
(3) The $14 \mathrm{kWp}$ PV system without using an EES system leads to a DA of $49 \%$. Since most of the demand coinciding with the PV generation is already covered by the $6 \mathrm{kWp}$ system, the DA of the $14 \mathrm{kWp}$ system increases by only $9 \%$, even though the PV system is more than doubled. Compared to (2), the DA can be significantly increased by using an EES system. With an EES capacity of $20 \mathrm{kWh}$, the DA is increased to $75 \%$.

The main results can be summarised as follows:

- The combination of the PV system with an EES system significantly increases the DA as well as the DSC.

- However, even with a large installed PV capacity of $16 \mathrm{kWp} \mathrm{(17.2}$ MWh/a) and a large EES capacity of $20 \mathrm{kWh}$, a maximum value of the DA, which primarily depends on consumer behaviour and the building structure, of about $77 \%$ is achieved.

- Further, at the same system size (PV: 16 kWp, EES: 20 kWh), a DSC of around $43 \%$ is achieved, i.e., approximately half of the generated energy is consumed by the prosumer him/herself. This discrepancy results from the seasonal difference between the generation and demand, with the highest generation during summer and the highest demand in winter.

\subsection{Impact of energy tariffs on prosumer behaviour}

The integration of new meter functions and services (smart metering) in hybrid energy systems such as prosumers will enable marketdependent dynamic or special consumer and prosumer tariffs. In the case of unprofitable feed-in tariffs, it can be economical to use the photovoltaic system's surplus generation on-site through demandside management and thus increase the degree of self-consumption, to buffer it in energy storages, or to cover the thermal demand (e.g., domestic hot water demand)

Therefore, the impact of tariff regimes commonly used in Austria on optimising prosumers, the static, high and low tariff (HT/NT) and a newly offered dynamic tariff are examined. Both the static and the HT/NT tariff are tariff models with fixed agreed costs for a defined annual energy demand over a contractual period. By using smart meters, a dynamic tariff model dependent on the electricity market is possible. The dynamic tariff is calculated based on a monthly rate, taxes, network service charges and variable energy costs depending on the electricity market.

An optimising prosumer's response to the different energy tariffs is analysed based on the thermal (TES) and electrical (EES) energy storage system's operation. The used thermal energy storage covers the domestic hot water demand by using heating cartridges. The parameter settings of the investigated prosumer can be found in Table 1

Figure 3 shows the state of charge (SoC) of the electrical (EES) and thermal (TES) energy storage system at the three chosen energy tariffs (static, HT/NT and dynamic tariff) during four exemplary selected days. Furthermore, the PV system's generation (dark gray area with black edge), the electrical energy demand (dark gray area) and the thermal demand (light gray area) are shown. Due to poor weather conditions, the PV systems' generation is reduced on day three and four. The demand shows equal time courses over investigated days.

\section{Static energy tariff}

At a static energy tariff, both storage systems - EES and TES are operating independently from the energy tariff. The prosumer's forecast-based storage management mainly depends on the energy generation of the PV system, the energy demand and the assumed investment and operating expenditures of the technologies. Mainly 


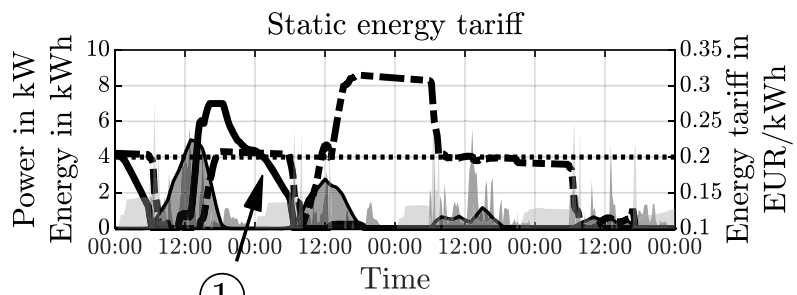

(1) Time

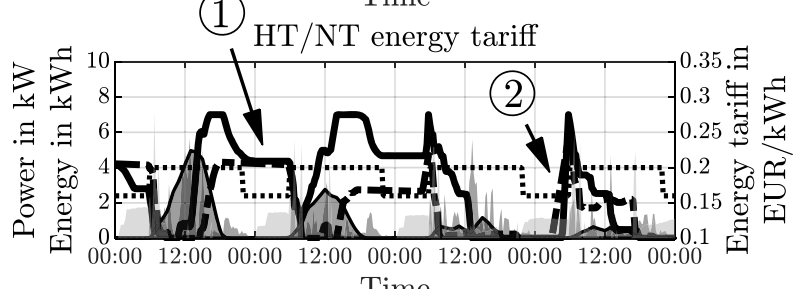

Time

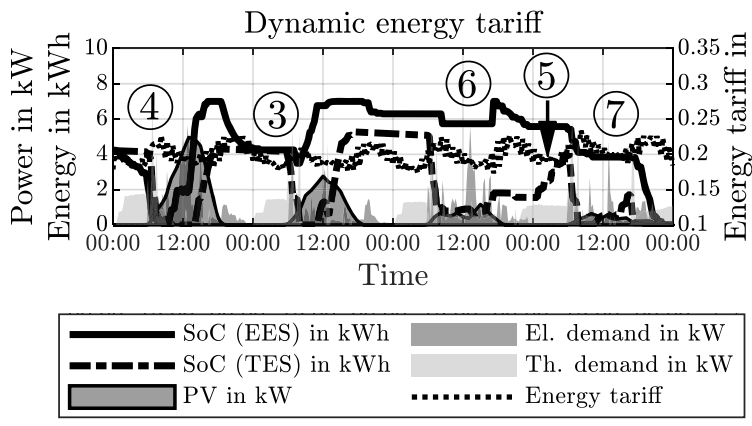

Fig. 3. Impact of energy tariffs on optimising prosumer storage charging behaviour

based on the assumed costs of the technologies, it is economically preferable to fully charge the TES system with the PV generation in the case of the upcoming poor weather conditions - decrease in PV generation - during the last two days instead of using the EES system. The stored energy in the TES is then used to cover the domestic hot water demand on the following poor weather days. Further shown in Fig. 3 (1) (static energy tariff), the EES system is used to cover the heat pump supplied heating demand at night, until the EES system completely discharged on the morning of day two.

\section{HT/NT energy tariff}

The storage management of the optimising prosumer is now reacting to differing electrical energy costs. The costs of the HT/NT tariff changes according to a given time range for the

- low load NT from 10 pm to 6 am (night-time) and

- high load HT from 6 am to 10 pm (day-time).

Comparing the HT/NT- with the static energy tariff in Fig. 3, marked with (1), it can be observed that at low tariff times (NT, $10 \mathrm{pm}$ to $06 \mathrm{am}$ ) and due to the prosumer's forecast-based operation, with an ideal weather, demand and tariff forecast of 72 hours, the EES system holds the state of charge and will not cover the heating demand. Later, at high tariff times (NT, 06 am to $10 \mathrm{pm}$ ), the prosumer's energy demand gets covered by the storages (EES and TES).

Further, as shown in Fig. 3 (2), at times of low or no PV generation and low tariff times, it can be observed that caused by the forecastbased operation the storage systems - EES and TES - are charged from the power network briefly before switching from NT to HT times. After switching from NT to HT, the charged energy is used to cover the prosumer's energy demand.

\section{Dynamic energy tariff}

The energy costs at dynamic tariff show a market-dependent periodically behaviour, as shown in Fig. 3. The energy costs decrease at times of high generation of the PV system and low load (night) and increase again at times of high loads, such as in the morning and evening.

Compared to the HT/NT tariff, a similar behaviour is observed for the dynamic tariff. At low tariff times (3), (6) and (7), mainly on midday and night, the storage systems holds their state of charge and will not cover the energy demand. At increasing energy costs (4), the storages - EES and TES - are then used to cover the energy demand. Similar to the HT/NT tariff (2), at times of low or no PV generation and low costs, caused by the forecast-based operation of the prosumer, the storage systems is charged, see (5), via the power network.

Since the low and high tariff times change more frequently in the dynamic energy tariff than the HT/NT energy tariff, the EES is barely used during the two bad weather days as almost no electrical energy is consumed at high tariff times and at low tariff times the demand gets preferably covered by the power network. Only on the last day - shown in Fig. 3 (7) - the EES is discharged early in the morning because the ideal 72 hours forecast predicts a high PV generation for the upcoming days (not shown in Fig. 3) and the opportunity to charge the storages again.

\section{Influence of optimising prosumers on rural distribution networks}

Subsequent, the developed simulation is used to analyse the influence of self-optimising prosumers on a rural distribution network. Therefore the simulation model is linked with load flow calculations of the power network. For the network analyses, the benchmark network "1-LV-rural1-0-sw" from the German project "SimBench" [6] is used.

The rural low-voltage distribution network of the benchmark network "1-LV-rural1-0-sw" shown in Fig. 4 consists of four feeders and a total of 13 households. The household loads and the decentralised generation systems from SimBench dataset are replaced by the developed simulation model of the optimising prosumer. Lowvoltage cables of the type NAYY $4 \times 150$ SE $0.6 / 1 \mathrm{kV}$ with a thermal rating of $270 \mathrm{~A}$ are used [6]. The low voltage network is fed by a $160 \mathrm{kVA}$ transformer from a $20 \mathrm{kV}$ medium-voltage network. In order to analyse the influence of prosumers on different feeder lengths and assuming a variable voltage level on the high-voltage side of the transformer, the following changes are made in contrast to the SimBench data sets:

- Additionally, a $10 \mathrm{~km}$ long medium-voltage cable is connected between the $20 \mathrm{kV}$ medium-voltage network and the transformer. The medium-voltage cable type A2XHCJ2YV 150 has a thermal rating of $319 \mathrm{~A}$ [7].

- The length of cable C5 extends from $50 \mathrm{~m}$ to $500 \mathrm{~m}$.

- The length of cable C13 extends from $133 \mathrm{~m}$ to $1000 \mathrm{~m}$.

The thirteen prosumers connected to the low-voltage network use linear optimisation algorithms to optimise the operation of their hybrid energy systems. There is no exchange of information between the prosumers nor is an so-called energy community formed. The optimisation objectives of the prosumers aims to individually maximise the degree of autonomy as well as minimising the annual energy costs.

The total installed photovoltaic capacity of $167 \mathrm{kWp}$ in the network is chosen as an extreme photovoltaic scenario. Nevertheless, the installed photovoltaic capacity per household falls within realistic limits. 


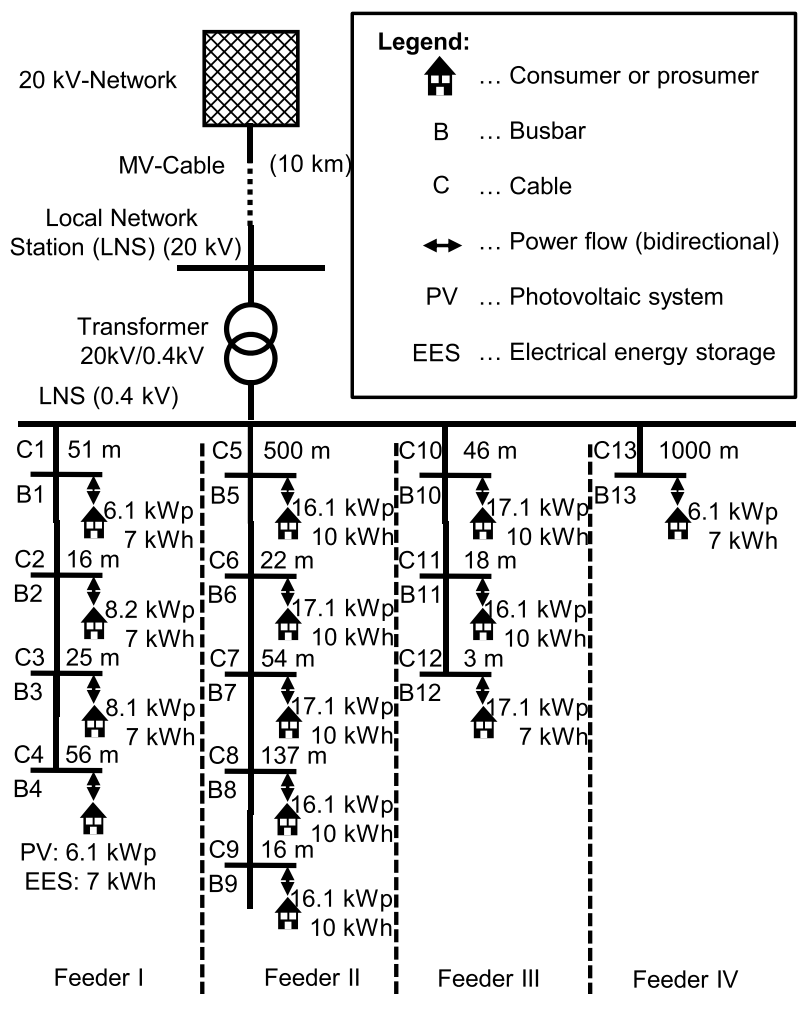

Fig. 4. Low-voltage network, consisting of four feeders and the considered thirteen prosumers

In the following analyses, the influence of optimising prosumers on the power network is investigated:

\section{Dynamic energy tariffs and peak-shaving}

The introduction of dynamic energy tariffs has a significant impact on prosumers' optimised operation when using energy storage systems. An optimising prosumer considering weather, demand, and tariff forecasts will react to changing energy tariffs and adapt the storage systems' charging and discharging behaviour accordingly, resulting possibly in increased electrical demand at unusual times. Therefore, the impact of optimising prosumers at such dynamic energy tariffs on the low-voltage network is analysed. Further, measures to limit the households peak power, such as peak-shaving, are being investigated.

Impact of voltage and reactive power control on the distribution network

In order to comply with the voltage limits according to EN 50160 [8] and the Austrian national rules TOR [9], the effectiveness of different methods for voltage and reactive power control are determined.

\subsection{Dynamic energy tariffs and peak-shaving}

Subsequently, the effects of economically optimising prosumers on the LV network are examined for different tariff situations and at a given power limitation at the PCC's. Figure 5 shows that at dynamic energy tariffs, the peak power of prosumers increases both in terms of power demand and surplus feed-in.

Dynamic energy tariffs and peak-shaving

Scenario N2 achieves the peak load in winter at times of no PV generation, a high heating and domestic hot water demand and at
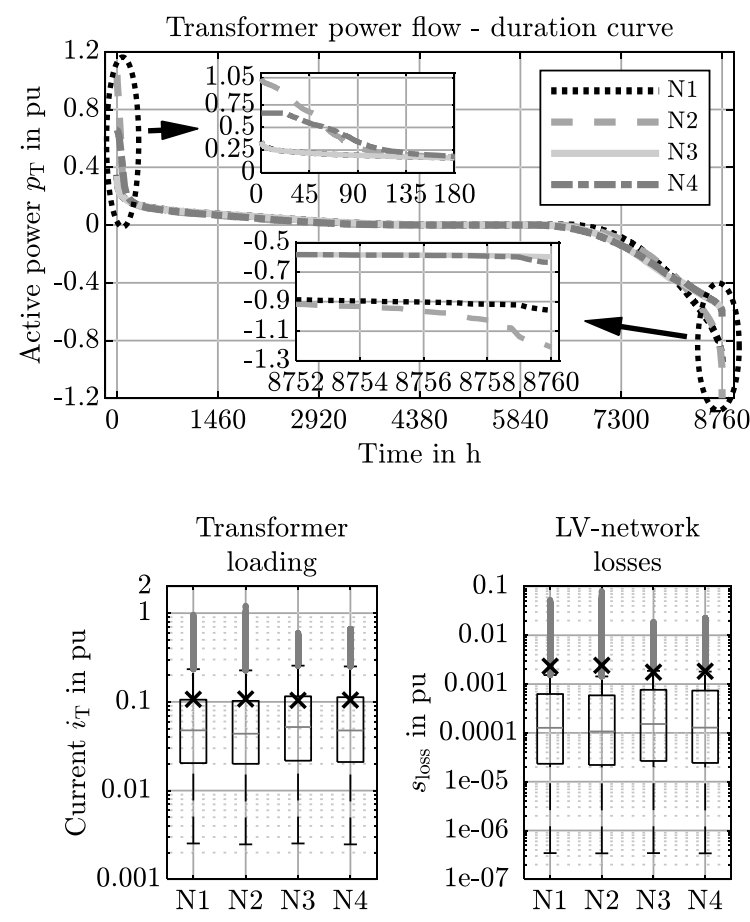

Fig. 5. Active power flow $p_{\mathrm{T}}$ across the transformer, transformer loading $i_{\mathrm{T}}$ and LV-network losses $s_{\text {loss }}-$ Scenario N1-N4.

N1: Heat pumps, thermal energy storages with heating cartridges, charging of the electric vehicles, PV, electrical energy storages, static energy tariffs and PCC limits set to $17.3 \mathrm{kVA}$;

N2: N1 with dynamic energy tariffs;

N3: N1 performing peak-shaving with PCC limits set to $8 \mathrm{kVA}$;

N4: N1 with dynamic energy tariffs and peak-shaving with PCC limits set to $8 \mathrm{kVA}$; Power flow: $\boldsymbol{p}_{T}>0$ : load flow from the MV- to the LVnetwork; $p_{\mathrm{T}}<0$ : load flow from the LV- to the MV-network; Box plots: Black crosses represent the average values

times of low energy costs. As a result of the low energy costs, almost all prosumers simultaneously charge their thermal energy storages via the power network. The electrical energy storages are not discharged at those times. Compared to scenario N1, in scenario $\mathrm{N} 2$, the maximum transformer load flow $p_{\mathrm{T}}$ from the MV-network increases from 0.348 pu to $1.040 \mathrm{pu}$.

In addition to peak load, the surplus feed-in to the LV network increases at times of high PV generation combined with high energy costs (purchase) and high feed-in tariffs in scenario N2. Nearly the entire PV generation of the prosumers is fed into the LV network. The energy storages will not be charged at those times. Compared to scenario N1, in scenario N2 the power in-feed into the MV network increases from $0.959 \mathrm{pu}$ to $1.208 \mathrm{pu}$.

The introduction of dynamic tariffs combined with optimising prosumers increases the purchasing power and feed-in power. In both cases - purchase and in-feed - the transformer gets overloaded at peak times a few five hours a year. However, the average transformer loading $i_{\text {T }}$ and network losses $s_{\text {loss }}$ in scenarios N1 and N2 remains almost the same.

\section{Peak-shaving}

By limiting the maximum power per household, the maximum transformer loading can be significantly reduced. This limitation of the power can be achieved by smart metering and, for example, 
by introducing power-based tariffs, at which exceeding a defined power limit for a specific time result in increased electricity costs.

A power limit of exemplary $8 \mathrm{kVA}$ at the PCC of the households is set in scenarios N3 and N4. The maximum transformer power flow $p_{\mathrm{T}}$ from the MV-Network to the LV-network in N2 is reduced by using peak-shaving in N4 by $37 \%$ from 1.04 pu to 0.659 pu (N4). Similarly, the maximum transformer power at surplus feed-in decreases by $51 \%$ from 1.208 pu (N2) to 0.634 pu (N4).

Performing peak-shaving, both the purchased peak power from the MV-network and the feed-in peak power to the MV-network can be significantly reduced.

\subsection{Impact of voltage and reactive power control on the distribution network}

Due to the optimising prosumers' operation and the in-feed of the surplus generation of the PV systems into the LV-network, the node voltages are influenced. To comply with the voltage limits according to EN 50160 [8] and the Austrian national rules TOR [9], the effectiveness of the following methods for voltage and reactive power control are determined.

Scenario N1 - Constant power factor mode

The generation plants of the prosumers operate at a constant power factor mode with a unity power factor $\cos (\varphi)=1$.

\section{Scenario N5 - Constant power factor mode}

To reduce the voltage rise in the rural network caused by the generation plants of the prosumers, a constant power factor $\cos (\varphi)=$ 0.95 (under-excited) is set.

\section{Scenario N6 - Voltage-reactive power mode}

To limit the voltage increase and voltage decrease, the voltagereactive power (volt-var) mode is used to actively control the reactive power output of the inverter as a function of the voltage $V$.

A dead band of $\pm 2 \% V_{n}\left(1 \mathrm{pu} \hat{=} V_{n}=0.4 \mathrm{kV}\right)$ as well as a droop of $2 \% V_{n}$ is set. According to the Austrian national rules TOR, the required reactive power capability for inverter-based generators $q_{\max }$ is set to $0.436 \mathrm{pu}$, corresponding to a power factor $\cos (\varphi)=0.9$.

\section{Scenario N7 - Active power-power factor mode}

The active power-power factor (watt- $\cos \varphi$ ) mode regulates the power factor $\cos (\varphi)$ piecewise linearly as a function of the active power $p$.

When reaching an active power of $p=0.5\left(1 \mathrm{pu} \hat{=} P_{\mathrm{r}}\right)$, the inverter operates in under-excited mode and reduces the power factor $\cos (\varphi)$ linearly to a minimum of $0.9 \mathrm{pu}$.

Figure 6 shows the node voltages of the busbars of the analysed LV-network. The limits of the node voltages are defined by the standard EN 50160 [8]. This standard specifies that the supply voltage in low-voltage networks may change by a maximum of $\pm 10 \%$ to the nominal voltage $V_{N}$. According to the Austrian national rules, TOR [9], a maximum voltage increase of $\Delta V=3 \%$ in the low-voltage network, caused by power generation plants at each node (house service connection) must be guaranteed.

Figure 6 shows that in feeder II, due to the long cable C5 (500 m) at the beginning of the feeder and the high installed power of PV systems of the prosumers, significant changes in the node voltages of the busbars B5 to B9 occur. In contrast, a shorter length of the cables, about 50 metres, in the feeder I and III lead to no significant voltage changes.

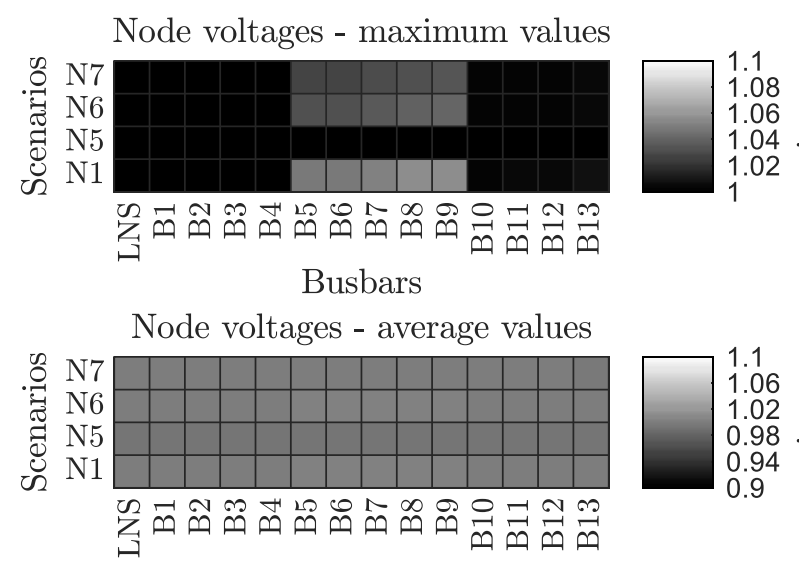

Busbars

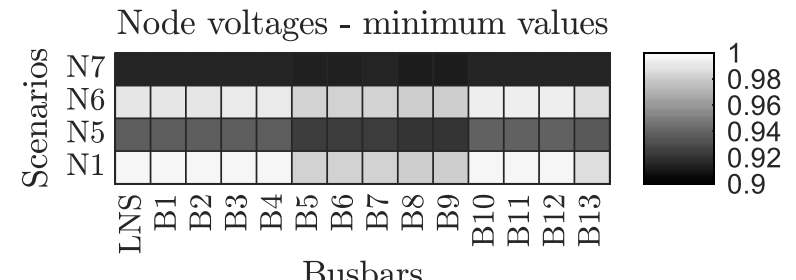

Fig. 6. Node voltages - scenarios N1, N5 to N7, busbars LNS and B1B13 (see Fig. 4)

N1: Heat pumps (heating demand), thermal energy storages with heating cartridges (domestic hot water demand), home charging of the electric vehicles, photovoltaic's, electrical energy storages, static energy tariffs, PCC limits set to $17.3 \mathrm{kVA}$ and the inverters are operating in a constant power factor mode $\cos (\varphi)=1$;

N5: N1, inverters are operating with a constant power factor of $\cos (\varphi)=0.95$ (under-excited);

N6: N1 and the inverters are operating in volt-var mode;

$\mathrm{N} 7: \mathrm{N} 1$ and the inverters are operating in $\operatorname{watt}-\cos \varphi$ mode

\section{Scenario N5 - Constant power factor mode}

At a unity power factor $\cos (\varphi)$ in scenario N1, a maximum voltage increase to $1.056 \mathrm{pu}$ and voltage decrease to 0.98 pu occurs at busbar B9. Setting a constant power factor $\cos (\varphi)$ of 0.95 (underexcited) in scenario N5, the maximum voltage increase caused by power in-feed of the generation plants is significantly reduced to a maximum node voltage of 1 pu for the entire network area compared to scenario N1.

The circumstance that at a constant power factor $\cos (\varphi)$ of 0.95 (under-excited) all inverters of the prosumers in the LV-network provide reactive power to the LV-network, leads to a significant voltage decrease in the entire network, reaching a minimum node voltage of $0.921 \mathrm{pu}$ at busbar B9. The node voltage at the LNS $(0.4 \mathrm{kV})$ is also affected significantly and is reduced to $0.937 \mathrm{pu}$.

\section{Scenario N7 - Active power-power factor mode}

Similar to a constant power factor $\cos (\varphi)$ in scenario N5, the watt- $\cos \varphi$ mode in scenario N7 also affects the node voltages in the entire network area equally.

In Scenario N7, the power factor $\cos (\varphi)$ is, starting from a power level of $p=0.5 \mathrm{pu}$, linearly reduced up to a minimum of 0.9 (underexcited) at $p=1 \mathrm{pu}$. The chosen power factor $\cos (\varphi)$ of 0.9 at $p=$ 1 pu results in high voltage decrease in the entire network and to a minimum node voltage at busbar B9 of 0.911 pu.

In comparison to scenario $\mathrm{N} 1$, the voltage increase caused by the prosumers' generation plants reduces significantly, with a maximum 

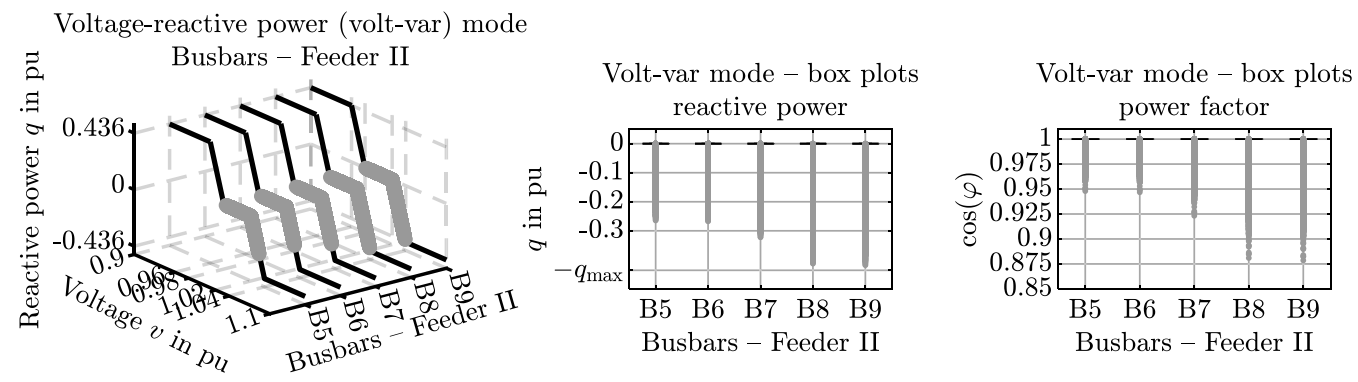

Active power-power factor (watt- $\cos \varphi$ ) mode

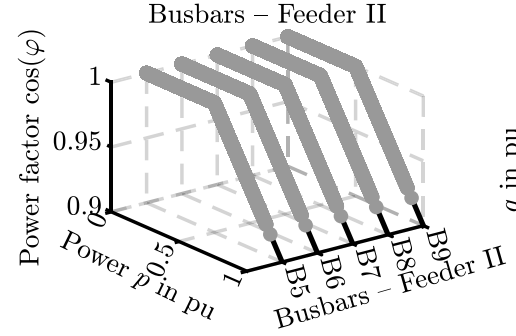

Watt-cos $\varphi$ mode - box plots reactive power

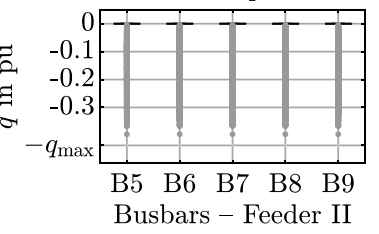

Watt- $\cos \varphi$ mode - box plots power factor

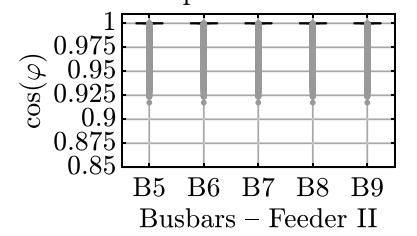

Fig. 7. Characteristic curves of the volt-var mode (left) and the watt- $\cos \varphi$ mode (right) for feeder II

reduction of the node voltage at busbar B9 from $1.056 \mathrm{pu}$ (N1) to $1.033 \mathrm{pu}$.

Scenario N6 - Voltage-reactive power mode

In scenario N6, the voltage-reactive power (volt-var) mode actively controls the inverter's reactive power output as a function of the respective node voltage (B1... B13), which leads to the lowest transformer loading as well as an effective voltage control. The volt-var mode offers more flexible control of the voltage than the watt-cos $\varphi$ mode. So it offers a good compromise between voltage level and provided reactive power than the watt- $\cos \varphi$ mode.

The generation plants connected to the feeders I, III and IV rarely provide reactive power as the voltage level is mostly between 0.98 pu and $1.02 \mathrm{pu}$ (dead band). However, only the generation plants at feeder II must actively provide reactive power to minimise the voltage increase. The maximum voltage increase at busbar B9 is decreased from $1.056 \mathrm{pu}$ (N1) to $1.039 \mathrm{pu}(\mathrm{N} 6)$.

Characteristic curves and operating range of voltage-reactive power mode and active power-power factor mode

Caused by the long cable lengths and the power in-feed of the generation plants in feeder II, the greatest need for reactive and voltage power control occurs here. Figure 7 shows the general characteristic curves and the operating range, based on the performed load flow calculations, for the volt-var mode, Scenarios N6, and the watt- $\cos \varphi$ mode, Scenario N7, for the generation plants of feeder II in detail.

Figure 7 (top left) shows the characteristic curve of the voltagereactive power (volt-var) mode of the prosumers of the feeder II at busbars B5 to B9. The gray dots show every moment the volt-var mode is actively providing reactive power to the network.

Generally, generation plants, operating in volt-var mode, at the beginning of the feeder do only slightly participate in reactive power control. The further away the generation plants are located from the feeding network (local network station), the higher their participation in reactive power control.

Figure 7 (down left) shows the characteristic curve of the watt- $\cos \varphi$ mode of the prosumers at the respective busbar. The gray dots show every moment the watt- $\cos \varphi$ mode is actively providing reactive power to the network. In contrast to the volt-var mode, the watt- $\cos \varphi$ mode reduces the power factor $\cos (\varphi)$, after reaching the setpoint of $p=0.5 \mathrm{pu}$, linearly to a minimum of $0.9 \mathrm{pu}$ (under-excited).

Compared to the volt-var mode, where generation plants at the end of the feeder must participate more in reactive power control, the watt- $\cos \varphi$ mode participates each generation plant equally in the voltage control.

\section{Conclusion}

In this contribution, a simulation model was used to model, simulate and analyse the behaviour and steady-state energy flows of hybrid energy systems of single-family houses. Using linear optimisation algorithms, the simulation model determined in a forecastbased manner the optimal use of decentralised energy generation and storage systems. Furthermore, the simulation model was used to analyse how the high penetration of optimising prosumers influences rural distribution networks.

The combination of photovoltaic systems with electrical energy storage systems can significantly increase the degree of autonomy as well as the degree of self-consumption of a prosumer. However, even with a large installed photovoltaic capacity of, e.g., $16 \mathrm{kWp}$ and a large electrical energy storage capacity of, e.g, $20 \mathrm{kWh}, \mathrm{a}$ maximum value of the degree of autonomy, which primarily depends on consumer behaviour and the building structure, of about $79 \%$ was achieved. With a degree of self-consumption of around $44 \%$, i.e., approximately half of the generated energy is consumed by the prosumer him/herself. This discrepancy results from seasonal differences between the generation and demand.

Photovoltaic and electrical energy storage systems require an optimal dimensioning of their system capacities. To achieve autarky $(\mathrm{DA}=100 \%)$, PV-Storage systems need to be dimensioned in a disproportionate size so as to cover the high energy demand in the winter season and during long periods of reduced energy generation caused by bad weather.

The use of time-varying energy tariffs also leads to changes in the prosumers' hybrid energy system's operation. An optimising prosumer considering weather, demand and tariff forecasts of, e.g., the 
next 72 hours, will react to changing energy tariffs to achieve an economic optimum as well as change the storage system's charging and discharging behaviour. The analyses reveals that with timevarying energy tariffs, the optimising prosumer's energy storages would possibly get charged at times of low or no PV generation and low costs, resulting in increased demand at unusual times.

The performed simulations reveal that the introduction of dynamic energy tariffs will fundamentally change prosumers' operation, directly influencing the load flow in distribution networks. The power increases significantly at the same energy demand, considering that households pay for the purchased or fed-in amount of energy (energy-based tariffs). Performing peak-shaving by setting power limits at the households' PCC the optimising prosumers' respective peak power is reduced.

The comparison of the voltage and reactiver power control methods showed that the volt-var mode offers more flexible control of the node voltage, with a good compromise between voltage level and the provided reactive power than the watt- $\cos \varphi$ mode. Otherwise, generators at the end of the feeder, in particular, must participate very intensively in reactive power control. Compared to the volt-var mode, in the watt- $\cos \varphi$ mode all generators participate regardless of their position in the network in reactive power control.

\section{Authors note}

This contribution represents an excerpt of the doctoral thesis by Mike Alexander Lagler [10].

Funding Note Open access funding provided by Graz University of Technology.

Publisher's Note Springer Nature remains neutral with regard to jurisdictional claims in published maps and institutional affiliations.

Open Access Dieser Artikel wird unter der Creative Commons Namensnennung 4.0 International Lizenz veröffentlicht, welche die Nutzung,
Vervielfältigung, Bearbeitung, Verbreitung und Wiedergabe in jeglichem Medium und Format erlaubt, sofern Sie den/die ursprünglichen Autor(en) und die Quelle ordnungsgemäß nennen, einen Link zur Creative Commons Lizenz beifügen und angeben, ob Änderungen vorgenommen wurden. Die in diesem Artikel enthaltenen Bilder und sonstiges Drittmaterial unterliegen ebenfalls der genannten Creative Commons Lizenz, sofern sich aus der Abbildungslegende nichts anderes ergibt. Sofern das betreffende Material nicht unter der genannten Creative Commons Lizenz steht und die betreffende Handlung nicht nach gesetzlichen Vorschriften erlaubt ist, ist für die oben aufgeführten Weiterverwendungen des Materials die Einwilligung des jeweiligen Rechteinhabers einzuholen. Weitere Details zur Lizenz entnehmen Sie bitte der Lizenzinformation auf http://creativecommons.org/licenses/by/4.0/ deed.de.

\section{References}

1. Kallrath, J. (2013): Gemischt-ganzzahlige Optimierung: Modellierung in der Praxis. 2nd ed. Wiesbaden, Germany: Springer.

2. Koop, A., Moock, H. (2018): Lineare Optimierung - eine anwendungsorientierte Einführung in Operations Research. 2nd ed. Berlin, Heidelberg, Germany: Springer.

3. Weniger, J., Bergner, J., Tjaden, T., Quaschning, V. (2015): In Dezentrale Solarstromspeicher für die Energiewende, 1st ed. Berlin, Germany: Berliner Wissenschafts-Verlag.

4. Ibrahim, S. H. (2013): Erstellung eines Berechnungstools zur Dimensionierung von Akkuspeichersystemen für netzgekoppelte Photovoltaikanlagen. Hochschule für Angewandte Wissenschaften Hamburg, M.S. thesis, Hamburg, Germany.

5. Hennings, W., Stenzel, P., Pflugradt, N. (2017): Performance of a photovoltaic plus battery home system with load prole scenarios changing over the system life. Energy Proc., 142, 3252-3257.

6. SimBench (2020): SimBench - Elektrische Benchmarknetzmodelle. Germany: Universität Kassel, Fraunhofer IEE, RWTH Aachen University, Technische Universität Dortmund. simbench.de

7. Wurzer, G. (2013): Verkabelung von Verteilernetzen $\leq 20$ kV. IEAN, TU Graz, M.S. thesis, Graz, Austria.

8. ÖVE (2010): Voltage characteristics of electricity supplied by public electricity networks. ÖVE/ÖNORM EN 50160:2010.

9. E-Control (2019): Technische und organisatorische Regeln für Betreiber und Benutzer von Netzen: TOR Erzeuger: Anschluss und Parallelbetrieb von Stromerzeugungsanlagen des Typs A und von Kleinsterzeugungsanlagen. E-Control. https://www.e-control. at/recht/marktregeln/tor.

10. Lagler, M. A. (2021): Influence of Optimising Prosumers on Rural Distribution Networks. IEAN, TU Graz, Doctoral thesis, Graz, Austria. 2021.

\section{Authors}

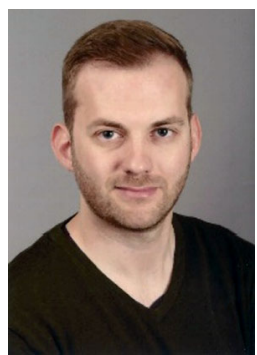

\section{Mike Alexander Lagler}

was born in Leoben/Austria in 1989 and received his Doctoral degree from Graz University of Technology in 2021. Since March 2016, Mike Lagler has been working as an university assistant at the Institute of Electrical Power Systems at Graz University of Technology. His research interests include hybrid energy systems, decentralised generation and storage systems, as well as the calculation and analysis of power networks.

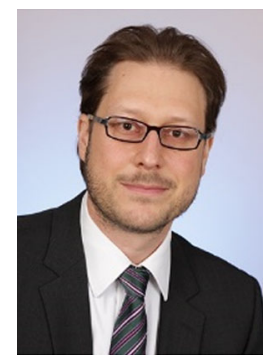

\section{Robert Schürhuber}

received his Ph.D. in electrical engineering from Vienna University of Technology in 2003. From 2003 to 2009 he worked in various fields of electrical power engineering for Siemens Energy, with focus on instrumentation and control. In 2010 he joined Andritz Hydro, where he worked as a senior expert in the Electrical Power Engineering department, with focus on the electrical behaviour of large hydro installations. Since October 2017 he is head of the Institute of Electrical Power Systems at Graz University of Technology. 